Portland State University

PDXScholar

$7-2013$

\title{
Putting Regulatory Data to Work at the Service of Public Health: Utilizing Data Collected Under the Clean Water Act
}

\author{
Jyotsna S. Jagai \\ US Environmental Protection Agency \\ Barbara J. Rosenbaum \\ Suzanne M. Pierson \\ Lynne C. Messer \\ Portland State University, lynne.messer@pdx.edu \\ Kristen M. Rappazzo \\ University of North Carolina at Chapel Hill
}

See next page for additional authors

Follow this and additional works at: https://pdxscholar.library.pdx.edu/commhealth_fac

Part of the Community Health Commons, and the Social Welfare Commons

Let us know how access to this document benefits you.

\section{Citation Details}

Jagai J, Rosenbaum BJ, Pierson SM, Messer LC, Rappazzo K, Naumova EN, Lobdell DT. Putting regulatory data to work at the service of public health: utilizing data collected under the clean water act. Water Quality, Exposure and Health, Epub July 2, 2013.

This Article is brought to you for free and open access. It has been accepted for inclusion in Community Health Faculty Publications and Presentations by an authorized administrator of PDXScholar. For more information, please contact pdxscholar@pdx.edu. 


\section{Authors}

Jyotsna S. Jagai, Barbara J. Rosenbaum, Suzanne M. Pierson, Lynne C. Messer, Kristen M. Rappazzo, Elena N. Naumova, and Danelle T. Lobdell 


\title{
Putting Regulatory Data to Work at the Service of Public Health: Utilizing Data Collected Under the Clean Water Act
}

\author{
Jyotsna S. Jagai - Barbara J. Rosenbaum - Suzanne M. Pierson - Lynne C. Messer · \\ Kristen Rappazzo $\cdot$ Elena N. Naumova $\cdot$ Danelle T. Lobdell
}

Received: 21 December 2012 / Revised: 4 June 2013 / Accepted: 6 June 2013 / Published online: 2 July 2013

(C) Springer Science+Business Media Dordrecht (outside the USA) 2013

\begin{abstract}
Under the Clean Water Act, the US Environmental Protection Agency (EPA) collects information from states on intended use and impairment of each water body. We explore the feasibility of using these data, collected for regulatory purposes, for public health analyses. Combining EPA impairment data and stream hydrology information we estimated the percent of stream length impaired for any use, recreational use, or drinking water use per county in the US as exposure variables. For health outcomes we abstracted county-level hospitalization rates of gastrointestinal infections, GI (ICD-9CM 001-009 excluding 008.45) and gastrointestinal symptoms, GS (ICD-9CM 558.9, 787) among US adults aged 65 years and older from the Center for Medicare and Medicaid Services (1991-2004). Linear mixedeffects models were used to assess county-level associa-
\end{abstract}

J.S. Jagai $(C)$ - D.T. Lobdell

National Health and Environmental Effects Research Laboratory, Office of Research and Development, US Environmental

Protection Agency, MD 58A, Research Triangle Park, NC, USA

e-mail: jagai.jyotsna@epa.gov

D.T. Lobdell (C)

e-mail: lobdell.danelle@epa.gov

B.J. Rosenbaum · S.M. Pierson

Innovate!, Inc., Alexandria, VA, USA

L.C. Messer

Center for Health Policy and Inequalities Research, Duke

University, Durham, NC, USA

K. Rappazzo

Gillings School of Global Public Health, University of North

Carolina, Chapel Hill, NC, USA

E.N. Naumova

Department of Civil and Environmental Engineering, Tufts

University School of Engineering, Medford, MA, USA tions between percent impaired waters and hospitalization rates adjusted for population density, a proxy for personto-person transmission. Contrary to expectation, both GI and GS were negatively associated with any water impairment in adjusted models (GI: $-0.052,95 \%$ CI: -0.077 , -0.028; GS: $-0.438,95 \% \mathrm{CI}:-0.702,-0.174)$. GI was also negatively associated with recreational water impairment ( -0.079 , 95 \% CI: $-0.123,-0.036$ after adjustment). Neither outcome was associated with drinking water impairment. Limited state data were reported to the EPA for specific recreational (27 states) and drinking (13 states) water impairment, thus limiting the power of the study. Though limited, this analysis demonstrates the feasibility of utilizing regulatory data for public health analyses.

Keywords Clean water act · Drinking water - Recreational water · Gastrointestinal infection · Mixed effects model

\section{Background}

It is estimated that in the US approximately 16.4 million cases of acute gastrointestinal illness per year are attributable to drinking water contamination (Messner et al. 2006). The sources of most waterborne pathogens are human and animal feces from infected individuals. These pathogens are either deposited directly into water bodies or transported to water bodies by surface or subsurface water flow. In urban areas, pathogens can also be transported by stormwater runoff, sewer overflows, and wastewater treatment plant effluents. Infection in humans can be caused directly via contact or ingestion of the contaminated waters or indirectly via contaminated food products (e.g., fish) or secondary, human-to-human, transmission. Most of the largescale waterborne disease outbreaks recorded in the US have 
been attributed to human contamination or failures in water treatment facilities. Between 1971 and 2006, 780 disease outbreaks were associated with drinking water contamination; of the 432 for which the etiology could be determined, 342 (79 \%) were associated with pathogen contamination (Craun et al. 2010). Between 2007 and 2008, 134 recreational water-associated outbreaks were reported in the US, primarily due to human fecal contamination or sewage (Hlavsa et al. 2011).

To reduce water contamination, the United States Clean Water Act (CWA) was established in 1972 to "restore and maintain the chemical, physical, and biological integrity of the Nation's waters" (US Environmental Protection Agency 2002, pg. 3). Section 305(b) of the CWA mandates states to assess the specific use of all waters in their jurisdiction and whether the overall water quality is adequate for intended uses. When the water quality does not meet its designated use, it is considered impaired. When water quality is impaired, states are required to identify problem areas, implement the necessary management actions to resolve the problems, and monitor the effectiveness of programs over time (US Environmental Protection Agency 2002). Under Section 303(d) of the CWA, states must develop a list of all impaired water bodies and prioritize these waters for restoration activities. Although designated water use, impairment, and remedial plans are mandated, reporting of these conditions is voluntary. The states voluntarily report to the EPA information regarding intended use of each stream length in the state and whether it is impaired for that particular use.

For the 2010 reporting cycle EPA summarized the water quality reports submitted by the states. States reported a total of 41,416 impaired water features, either stream lengths or lakes, with 71,889 causes of impairment (multiple causes can be listed for a water feature). The primary causes of impairment were pathogens $(10,704)$, metals (not including mercury) $(7,621)$, nutrients $(6,919)$, organic enrichment/oxygen depletion (6,368), sediment (6,199), polychlorinated biphenyls (PCBs) $(5,455)$, and mercury $(4,747)$ (US Environmental Protection Agency 2011b). All of these causes of water impairment have been associated with various public health concerns, including gastrointestinal illness (Craun et al. 2010) and developmental health outcomes such as low birth weight (Kim et al. 2011; Majidi et al. 2012).

In addition to being used for environmental monitoring and policy making, data collected for regulatory purposes are often used for public health research as proxies for environmental exposure. The most commonly used regulatory data in public health research are air pollution data collected under the Clean Air Act. These regulatory data were first used to draw associations between air pollution and mortality (Dockery et al. 1993; Kelsall et al. 1997) and are, more recently, being used to look at these associations with different size particulate matter (Zanobetti and Schwartz 2009).
The Toxics Release Inventory (TRI) which was established under the Emergency Planning and Community Right-toKnow Act (EPCRA) (US Environmental Protection Agency 2011d) has also been used as a proxy for chemical exposure. These data have been used to demonstrate an increased risk of non-Hodgkin lymphoma for residents who lived near chemical or petroleum facilities for 10 years (De Roos et al. 2010) and an increased risk of a diagnosis of brain cancer before the age of 5 years if the mother lives within one mile of a TRI facility (Choi et al. 2006). Under state regulation in California, comprehensive data on pesticide use is collected (California Department of Pesticide Regulation 2011). These data have been used as a proxy for pesticide exposure to assess risk of fetal death (Bell et al. 2001a), fetal death due to congenital anomalies (Bell et al. 2001b), and autism spectrum disorders in children (Roberts et al. 2007). These studies demonstrate regulatory data can be used to gain critical public health insights regarding the relationship between environmental exposure and health.

Given that data collected for environmental regulation have been used successfully for public health analysis, this study explored the use of water impairment data collected under the Clean Water Act, which, to our knowledge, has not been explored for use in public health analysis. In this study, we conduct a county-level analysis to assess associations between three types of water impairment and rates of hospitalization for gastrointestinal illness. We expect that counties with more impaired waters, particularly for drinking and recreational uses, will have higher rates of gastrointestinal illness.

\section{Methods}

\section{Exposure data}

We obtained impairment and water quality standards (WQS) data for the most recent state reported data which was collected under Sections 303(d) and 305(b) of the Clean Water Act (CWA). The CWA is administered at the state level and data are voluntarily reported from the states to the federal level. The dates of the reported data ranged from 2004 to 2010 as the federal reporting system maintains only the most recent data reported by each state. Under Section 305(b) of the CWA, states establish water quality standards for each hydrological feature based on the expected use (or uses) of these waters. Under Section 303(d) of the Clean Water Act, states assess whether waters are impaired (do not meet the standards) for the use(s) established in the WQS. This assessment is conducted biennially and the states voluntarily report these data to the federal level.

We estimated county-level impaired stream length for the contiguous US using impairment and WQS data. With the 
Fig. 1 Flow chart of data used to construct exposure variables
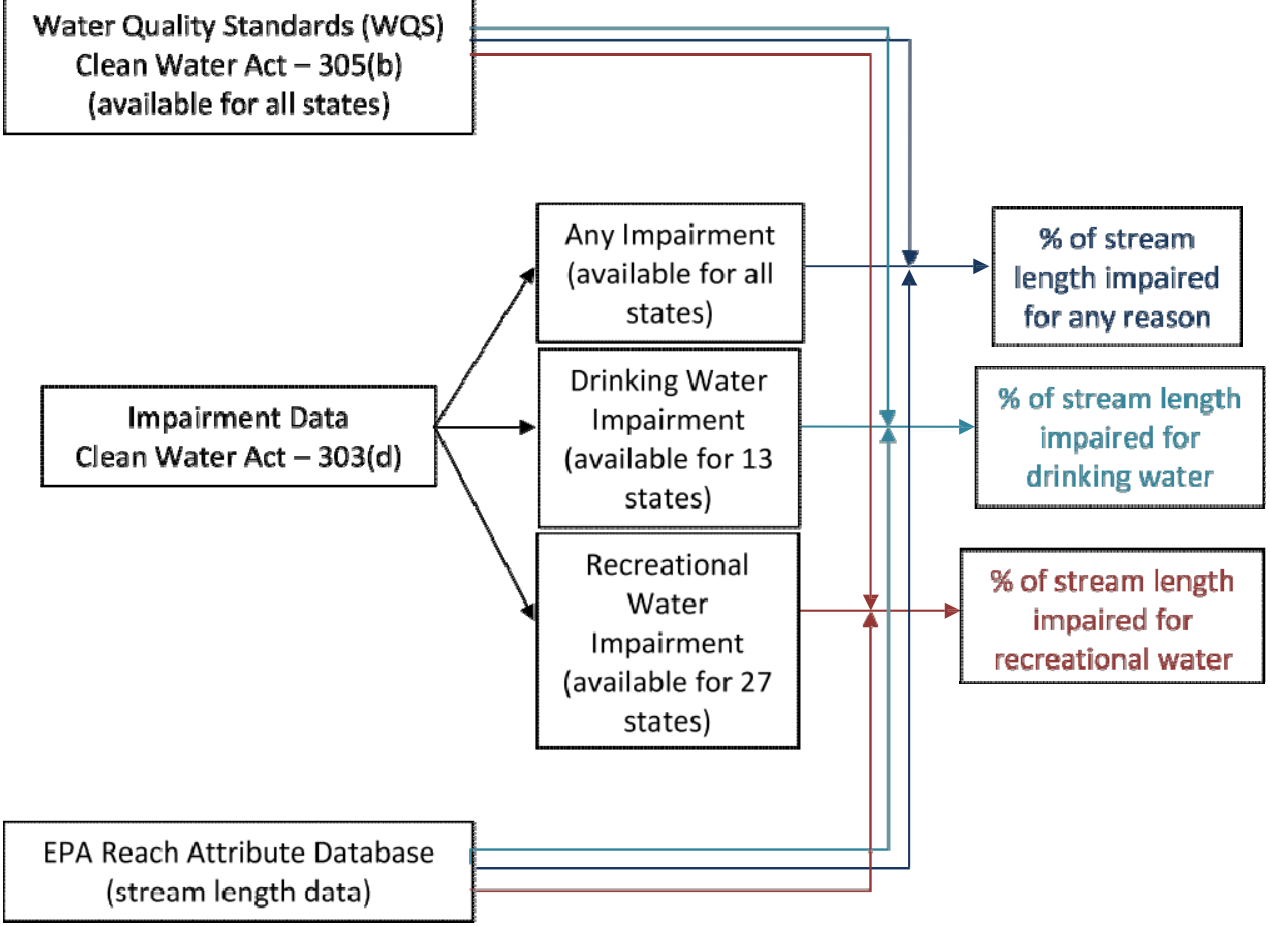

designated uses listed for each state, we classified the WQS into five broad categories of water use: agriculture, drinking water, recreation, wildlife, and industry. From these five categories, we utilized three measures of impairment as exposures of interest for this analysis: percentage of stream length impaired for i) any reason, ii) recreational water use, and iii) drinking water use.

Using Geographic Information Systems (GIS) we calculated county-level percentages of impairment. WQS and impairment datasets were joined to the map layer of hydrologic features in EPA's Reach Attribute Database (RAD) - a replicate of the National Hydrography Dataset Plus (NHDPlus) augmented for reporting water quality data. We joined our defined broad water use categories to the WQS data and created a table summarizing hydrologic features with multiple uses. By implementing GIS network and event tools, which link tabular database information with linear or polygon features, we assigned WQS and impairment tables to features in the RAD. Stream lengths were clipped by county boundaries in order to calculate percent impairment by county. For this analysis, we included only linear water features in each category and excluded polygon features such as lakes due to the lack of well-defined county and state boundaries across water bodies. Next, county and state designations were linked with linear features in RAD. Once all data was associated to linear hydrologic features, lengths were calculated water features impaired for any use, drinking water use, or recreational use, and for all stream length within a county. Using this information we estimated percent of stream length impaired per county intended for any use, drinking water, and recreational water. Figure 1 provides a flowchart of the datasets used to calculate these exposure measures.

\section{Outcome Data}

For health outcome data, we utilized hospitalization records from the Center for Medicare and Medicaid Services (CMS). These data are the most comprehensive national-level data for hospitalization available in the US Hospitalization records for persons aged $\geq 65$ years were abstracted for all counties in the US for a 14-year period (January 1, 1991December 31, 2004). About $96 \%$ of all adults aged $\geq 65$ years are CMS beneficiaries, therefore, their hospitalization records are included in this dataset (Cohen and Naumova 2007; Fisher et al. 1990). Each hospitalization record contains individual patient information including state of residence, sex, age at admission, dates of admission and discharge, and ten ICD-9-CM system diagnosis codes. For this analysis, we considered two outcomes and abstracted data which included the following diagnoses in any of the ten diagnosis codes: gastrointestinal symptoms (GS) —ICD 558.9, 787 and all gastrointestinal infections without Clostridium difficile (GI)_-ICD 001-009 excluding 008.45. We removed Clostridium difficle as it is primarily a nosocomial infection (McFee 2009b, 2009a). Hospitalization records were aggregated according to each patient's diagnosis code and residential county. To minimize spurious high rates caused by extremely low denominators, a spatial aggregation scheme was applied to incorporate counties with low elderly population into the adjacent counties until the total number of 
Fig. 2 Annual rate (1991-2004) of hospitalization for all gastrointestinal infections (ICD 9CM 001-009 w/o 008.45) per 10,000 elderly (65+ years old)

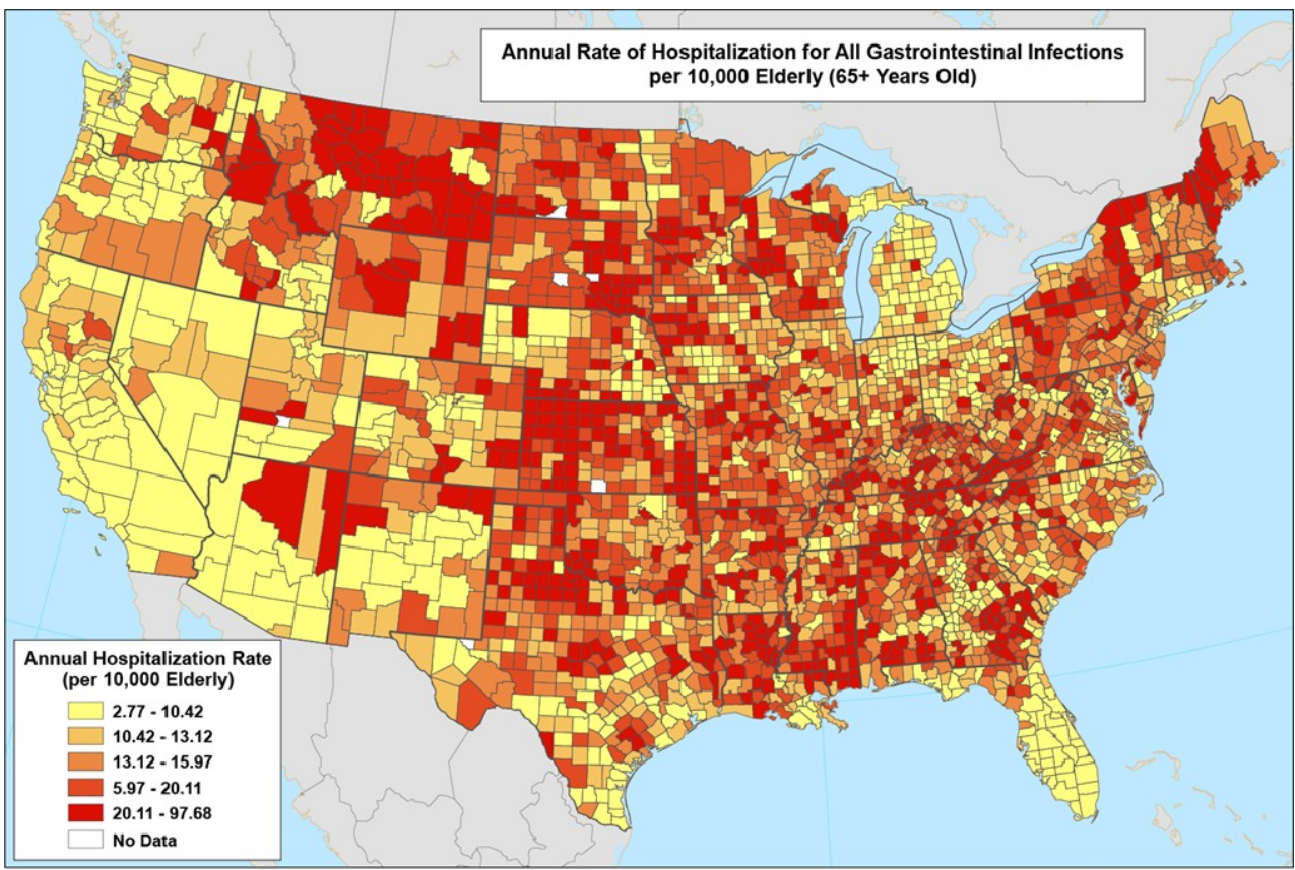

elderly exceeded 1,000 within the county aggregations, resulting in a total of 2792 counties, of the 3141 counties in the US, for analysis (for details related to aggregation rules see Castronovo et al. 2009). Average annual rate, per 10,000 elderly, was calculated for each outcome for each county using the linearly interpolated elderly population for 1997 (midpoint of data timeframe) as the denominator. The 1997 elderly population was interpolated from 1990 and 2000 US Census Bureau Data.

\section{Covariates}

County-level population density values were gathered from the 2000 US Census Bureau Data and used as a covariate in our analysis to control for potential person-to-person transmission of gastrointestinal infections (Cohen et al. 2008).

Analysis

We used a linear mixed-effects model (1) to assess the rate of gastrointestinal symptoms (GS) or all gastrointestinal infections (GI) with any water impairment, drinking water impairment, and recreational water impairment for counties with available data.

$Y_{i j}=\beta_{0}+\beta_{1} X_{i}+b_{0 i}+b_{1 i} x_{i j}$

where:

$Y_{i j}=$ outcome rates (GS or GI) for the $i$ th state and the $j$ th county,

$X_{i}=$ indicator variable for the $i$ th state, $x_{i j}=$ exposure measurement (using percent of stream length impaired for any use, drinking water use, or recreational water use in separate models) for the $i$ th state and the $j$ th county.

In this model $X_{i}$ represents a fixed effect as each state administers the regulations and $x_{i j}$, the percentage of water impairment, accounts for a random effect. We also ran models adjusting for county-level population density to control for person-to-person transmission.

Six mixed-effects models were fit for each outcome, GS and GI: 1) percent of any water impairment in the county, 2) percent of any water impairment in the county adjusting for population density in county, 3) percent of recreational water impairment in the county, 4) percent of recreational water impairment in the county adjusting population density in the county, 5) percent of drinking water impairment in the county, and 6) percent of drinking water impairment in the county adjusting for population density in the county.

ArcGIS 10.0 (ESRI, Redlands, CA) was used for geographic data processing and statistical analysis was conducted using $\mathrm{R}$ version 2.14.1.

\section{Results}

Annual rates of hospitalization for all gastrointestinal infections (GI) ranged from 2.77 per to 97.68 per 10,000 elderly (mean 15.92 \pm standard deviation 7.46). Annual rates of hospitalization for gastrointestinal symptoms (GS) ranged from 28.26 to 561.29 per 10,000 elderly (mean $181.85 \pm$ standard deviation 58.40). The high rates of hospitalization 
Fig. 3 Annual rate (19912004) of hospitalization for gastrointestinal symptoms (ICD 9CM 558.9, 787) per 10,000 elderly (65+ years old)

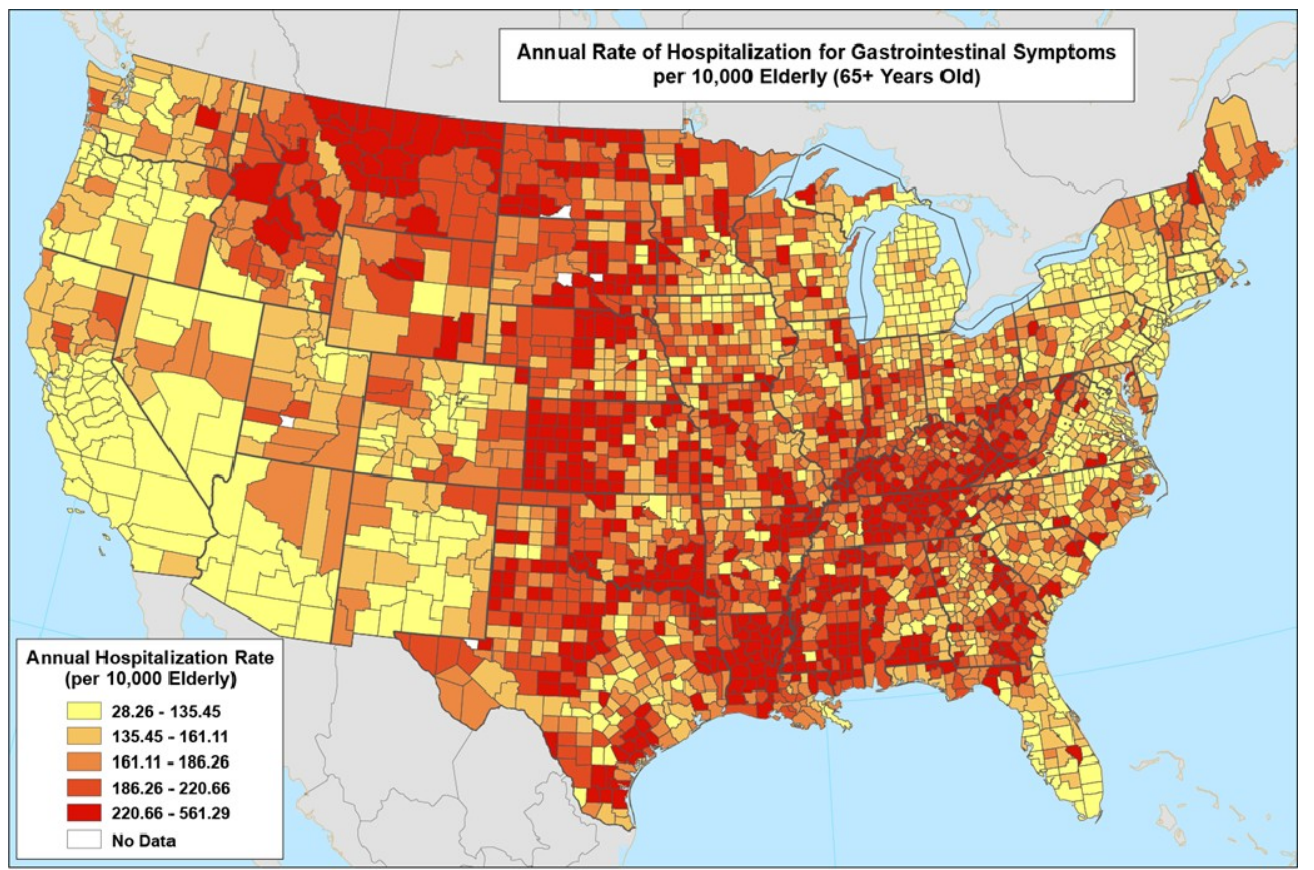

Fig. 4 Percentage of stream length in the county impaired for any use. Data available for 2610 of 2792 counties

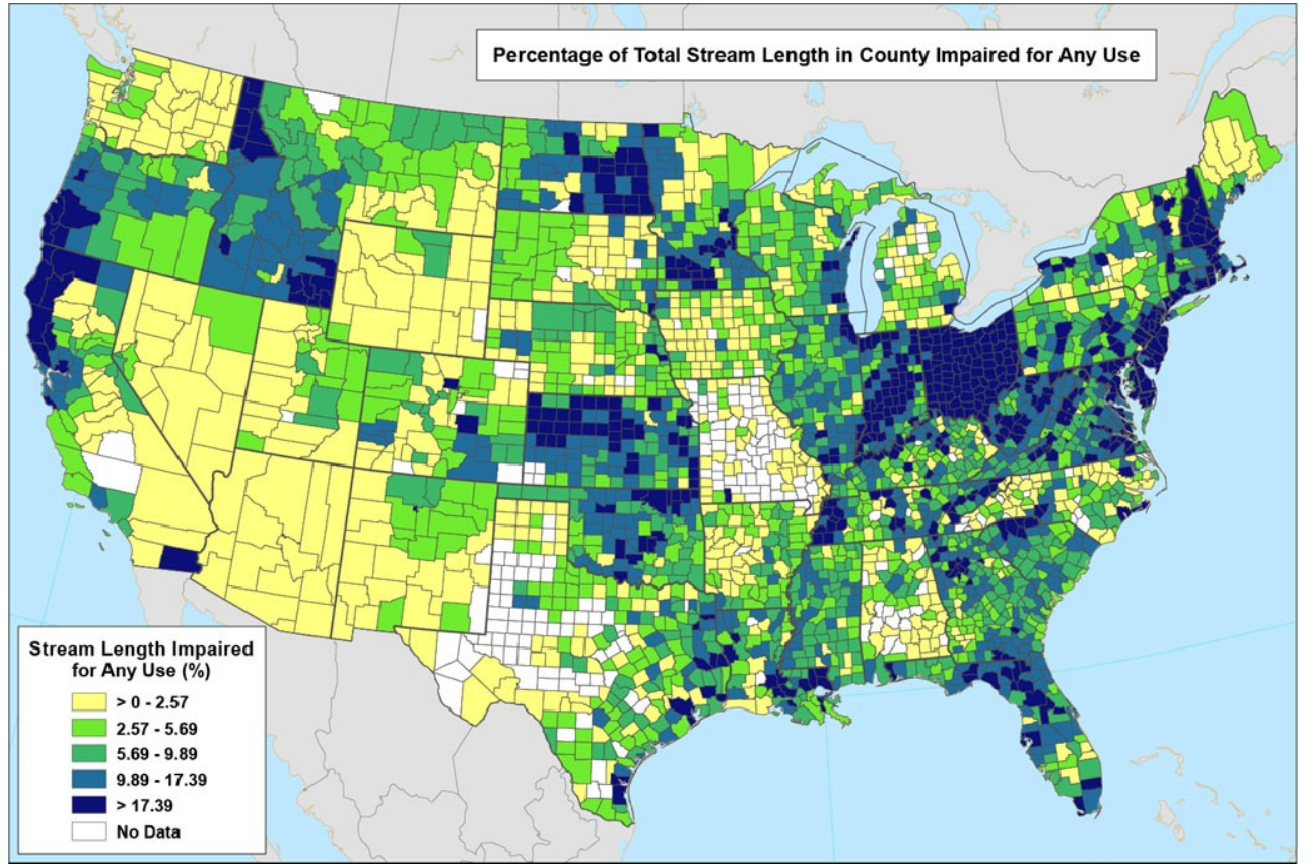

for GI in the elderly were distributed throughout the country (Fig. 2), whereas the highest rates for hospitalization for GS (Fig. 3) were seen primarily in the central plains and the Ohio River Valley.

The percent impairment for any use ranged from $0.00 \%$ to $98.50 \%$ (mean $12.35 \% \pm$ standard deviation $15.63 \%$ ). The percent impairment for recreational use ranged from $0.00 \%$ to $55.60 \%$ (mean $10.74 \% \pm$ standard deviation $10.80 \%$ ) and percent impairment for drinking water use ranged from $0.00 \%$ to $27.56 \%$ (mean $3.27 \%$ 土 stan- dard deviation $3.52 \%)$. Data on water impairment was severely limited due to lack of reporting from the state to the federal level. Impairment information was available for all states; however, only 27 states had data for all counties (Fig. 4). Data on any water impairment was available for 2610 (93.5 \%) of the 2792 counties. Drinking water impairment data were only available for 13 states and of those only two states, Connecticut and Nevada, provided data for all counties (Fig. 5). Reporting of recreational water impairment was more complete, yet data were only available for 27 
Fig. 5 Percentage of stream length in the county impaired for drinking water. Data available for 274 of 2792 counties
Fig. 6 Percentage of stream length in county impaired for recreational use. Data available for 1374 of 2792 counties
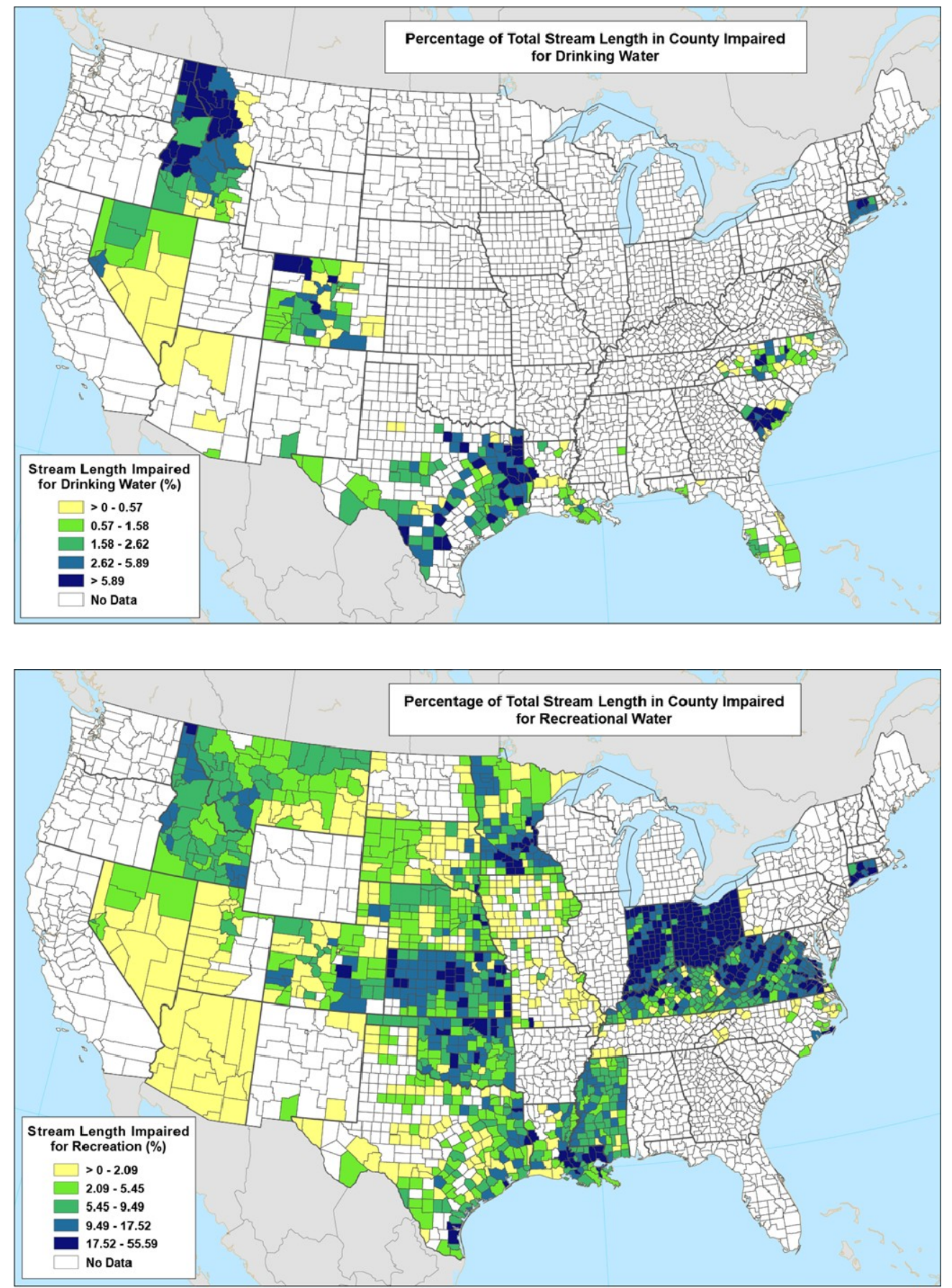

states of which only eight states provided data for all counties (Fig. 6). Thus, in the presented analysis, drinking water and recreational water impairment data were available for only 274 (9.8\%) and 1374 (49.2\%) of the 2792 counties, respectively.

All GI demonstrated a negative association with any water impairment (Table 1). However, this association was weak (-0.052, 95 \% CI: $-0.077,-0.028$ adjusted for population density). A one percent increase in water impaired for any reason was associated with a decline in the county rate of all gastrointestinal infections on average, by 0.052 per 10,000 elderly. The association between gastrointestinal symptoms and any water impairment was stronger but still negative ( -0.438 , 95 \% CI: $-0.702,-0.174$ adjusted for population density). GI demonstrated a negative association with recreational water impairment (-0.076, 95 \% CI: $-0.123,-0.025$ adjusting for population density). This association was not seen for gastrointestinal symptoms. Drinking water impairment was weakly negatively associated with GI (-0.010, 95 \% CI: $-0.220,0.201$ adjusting for popula- 
Table 1 Regression parameters

unadjusted and adjusted (for population density in county) models for two outcomes, county specific annual rates of all gastrointestinal infections and gastrointestinal symptoms

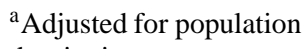
density in county

\begin{tabular}{|c|c|c|c|c|}
\hline & \multicolumn{2}{|l|}{ (GI) } & \multicolumn{2}{|l|}{ (GS) } \\
\hline & $\bar{\beta}$ & 95 \% CI & $\bar{\beta}$ & $95 \% \mathrm{CI}$ \\
\hline \multirow{2}{*}{$\begin{array}{l}\text { Any water impairment with } \\
\text { adjustment }^{\mathrm{a}}\end{array}$} & -0.047 & $(-0.070,-0.023)$ & -0.364 & $(-0.619,-0.109)$ \\
\hline & -0.052 & $(-0.077,-0.028)$ & -0.438 & $(-0.702,-0.174)$ \\
\hline \multirow{2}{*}{$\begin{array}{l}\text { Recreational water impairment } \\
\text { with adjustment }^{\mathrm{a}}\end{array}$} & -0.076 & $(-0.127,-0.026)$ & -0.268 & $(-0.676,0.139)$ \\
\hline & -0.076 & $(-0.127,-0.025)$ & -0.336 & $(-0.751,0.080)$ \\
\hline \multirow{2}{*}{$\begin{array}{l}\text { Drinking water impairment } \\
\text { with adjustment }^{\mathrm{a}}\end{array}$} & -0.064 & $(-0.292,0.164)$ & 0.561 & $(-0.929,2.050)$ \\
\hline & -0.010 & $(-0.220,0.201)$ & 0.721 & $(-0.765,2.207)$ \\
\hline
\end{tabular}

tion density) but positively associated with GS (0.721, $95 \%$ CI: $-0.765,2.207$ adjusting for population density).

\section{Discussion}

Data collected for regulatory purposes can be an untapped resource for public health analyses. In this paper, we demonstrate the feasibility of using of water impairment data collected under the Clean Water Act, which has not been previously used in association with health outcomes. We developed a novel method to calculate the percentage of overall stream length in the county impaired for various uses and assessed associations between county-level measures of water impairment and hospitalization rates for gastrointestinal illness. Calculating impairment rate by a meaningful unit of measure-in this case, stream length per county-is necessary to utilize the data for health analysis.

Data on impairment of water bodies for various intended uses are maintained and administered at the state level, then reported on a voluntary basis by the states to the federal level. There is significant variability in implementation of the regulation and reporting between the states, as is clearly demonstrated by the limited availability of data for drinking water and recreational water impairment with only 13 and 27 states providing data, respectively. Only the latest update of impairment data is maintained at the federal level (US Environmental Protection Agency 2011c); historic data are purged with each new data upload. Therefore, in our analysis the outcome data temporally precedes the exposure data. We consider the water impairment data as a marker of overall poor water quality and as an underlying latent condition rather than an acute exposure.

The limited reporting of state maintained data to the federal level constrains the power of our analysis. This is demonstrated in the inconsistency of results and through the wide confidence intervals. The analysis was conducted for the one state, Idaho, which had complete data for all counties and results were similar to those for all states (not shown). Additionally, data on water impairment were missing for several states and may bias our results as the reporting of state-level data to the federal system may not be random. For instance, states which have poor water quality may not report specific impairment data to the federal system. Another factor restricting states from reporting impairment data to the federal level is that the federal system requires uploading data in a Geographic Information System (GIS) database (US Environmental Protection Agency 2011c). This requirement can be limiting for states which may not have the expertise, staff, or budget to maintain and upload data in the required format.

We found that drinking water impairment was negatively associated with gastrointestinal infections and positively associated with gastrointestinal symptoms. Previous studies relating drinking water quality and gastrointestinal illness have produced varying results as well. The most commonly used measure of drinking water quality is turbidity, a measure of solids and particles suspended in water, often used as a surrogate measure for pathogen contamination. Reported higher daily water turbidity has been associated with an increased risk of gastrointestinal events (Morris et al. 1996) and with an increased risk of self-reported gastrointestinal illness at a lag of 2 days (Egorov et al. 2003). In Philadelphia, an increase in effluent drinking water turbidity was associated with an increase in emergency room visits for gastrointestinal illness in both the pediatric (Schwartz et al. 1997) and elderly populations (Schwartz et al. 2000) though the exposure measure for these studies has been criticized (Sinclair and Fairley 2000). Additionally, a study conducted in Atlanta demonstrated only a modest association between turbidity and emergency room visits for gastrointestinal illness (Tinker et al. 2010), while a study conducted in Edmonton, Canada found no association between effluent water turbidity and GI (Lim et al. 2002). Our findings, though contrary to our expectations, are not completely surprising. Most studies conducted on drinking water quality consider individual-level data for a specific area, city or beach, whereas we were using less specific county-level exposures which will move the estimates towards the null. We are also utilizing hospitalization data for this study which captures only the most severe cases of gastrointestinal illness as most people are not likely to be hospitalized for gastrointestinal 
conditions. Additionally, drinking water impairment standards include the caveat that the waters will be acceptable for drinking 'after' treatment (US Environmental Protection Agency 2011c). Therefore, with high quality water treatment facilities in the US, drinking water impairment is not expected to be a good proxy for human exposure.

In our study, we found a negative association between GI and recreational water impairment. Previous studies have demonstrated positive associations between recreational water quality and risk for gastrointestinal illness. The most common measures of bacterial contamination in recreational waters are enterococci, fecal coliform, and E. coli and these indicators have generally shown associations with gastrointestinal symptoms among swimmers (Pruss 1998; Wade et al. 2003). We expected recreational water impairment to be a better proxy for human exposure in our study. However, we are using county-level aggregates of exposure which will move the estimates towards the null and hospitalization data which represents only the most severe cases of gastrointestinal illness. Additionally, the negative association with recreational water quality is not unexpected as it is likely that community members are often alerted and aware that the recreational waters in their area may be unsafe and therefore may choose alternative locations for water recreation activities.

This analysis demonstrates the feasibility of using data collected for regulatory purposes, under the Clean Water Act, for public health analysis. We developed novel methodology to calculate county-level measures of water impairment for various uses. Despite limitations, we demonstrate that this impairment measure can be constructed and used for health analysis. The ability to utilize regulatory data collected under mandate is advantageous, particularly during times of reduced funding (Rotkin-Ellman et al. 2008). Air pollution data collected under the Clean Air Act mandates are commonly used for public health analyses (Dockery et al. 1993; Kelsall et al. 1997; Zanobetti and Schwartz 2009) because, while most air monitors are maintained by the states (US Environmental Protection Agency 2011a), reporting of the data, which is often collected daily or even more frequently, to the federal level is required (US Environmental Protection Agency 2011a). Therefore, routinely monitored data on air pollution are available at higher spatial and temporal resolutions than the water impairment data. Poor water quality can have a significant impact on the health of the community so it is necessary to understand these associations. Though limited for national-level analyses, these impairment data could be used for state-level analyses. Additionally, with increased reporting by states to the federal level, the data collected under the Clean Water Act would be more beneficial for public health analyses.

Acknowledgements The Office of Research and Development (ORD), US Environmental Protection Agency (EPA), partially funded the research with Innovate!, Inc. and L.C. Messer (Contracts WCF DP26H0001 and EP09D000003) and under EPA Cooperative Agreement with the University of North Carolina at Chapel Hill (CR83323601) and an appointment to the Research Participation Program for the US Environmental Protection Agency, Office of Research and Development, administered by the Oak Ridge Institute for Science and Education through an interagency agreement between the US Department of Energy and EPA. The authors would also like to thank Joel Hansel, EPA Region 4, and Andrey Egorov, World Health Organization, for their help in the initial phases of this project.

Conflict of interest The authors have no conflict of interest to declare.

\section{References}

Bell EM, Hertz-Picciotto I, Beaumont JJ (2001a) Case-cohort analysis of agricultural pesticide applications near maternal residence and selected causes of fetal death. Am J Epidemiol 154(8):702-710

Bell EM, Hertz-Picciotto I, Beaumont JJ (2001b) A case-control study of pesticides and fetal death due to congenital anomalies. Epidemiology 12(2):148-156

California Department of Pesticide Regulation (2011) Pesticide use reporting

Castronovo DA, Chui KKH, Naumova EN (2009) Dynamic maps: a visual-analytic methodology for exploring spatio-temporal disease patterns. Environ Health 8:61

Choi HS, Shim YK, Kaye WE, Ryan PB (2006) Potential residential exposure to toxics release inventory chemicals during pregnancy and childhood brain cancer. Environ Health Perspect 114(7):1113-1118

Cohen SA, Egorov AI, Jagai JS, Matyas BT, DeMaria A Jr., Chui KK, Griffiths JK, Naumova EN (2008) The SEEDs of two gastrointestinal diseases: socioeconomic, environmental, and demographic factors related to cryptosporidiosis and giardiasis in Massachusetts. Environ Res 108(2):185-191

Cohen SA, Naumova EN (2007) Population dynamics in the elderly: the need for age-adjustment in national BioSurveillance systems. In: Zeng D, Gotham I, Komatsu K et al (eds) Intelligence and security informatics: biosurveillance: second NSF workshop, BioSurveillance 2007, vol 1, New Brunswick, NJ, USA, May 22, 2007. Lecture notes in computer science, vol 4506. Springer, Berlin, pp 47-58.

Craun GF, Brunkard JM, Yoder JS, Roberts VA, Carpenter J, Wade T, Calderon RL, Roberts JM, Beach MJ, Roy SL (2010) Causes of outbreaks associated with drinking water in the United States from 1971 to 2006. Clin Microbiol Rev 23(3):507-528

De Roos AJ, Davis S, Colt JS, Blair A, Airola M, Severson RK, Cozen W, Cerhan JR, Hartge P, Nuckols JR, Ward MH (2010) Residential proximity to industrial facilities and risk of non-Hodgkin lymphoma. Environ Res 110(1):70-78

Dockery DW, Pope CA 3rd, Xu X, Spengler JD, Ware JH, Fay ME, Ferris BG Jr, Speizer FE (1993) An association between air pollution and mortality in six US cities. N Engl J Med 329(24):1753-1759

Egorov AI, Naumova EN, Tereschenko AA, Kislitsin VA, Ford TE (2003) Daily variations in effluent water turbidity and diarrhoeal illness in a Russian city. Int J Environ Health Res 13(1):81-94

Fisher ES, Baron JA, Malenka DJ, Barrett J, Bubolz TA (1990) Overcoming potential pitfalls in the use of Medicare data for epidemiologic research. Am J Publ Health 80(12):1487-1490

Hlavsa MC, Roberts VA, Anderson AR, Hill VR, Kahler AM, Orr M, Garrison LE, Hicks LA, Newton A, Hilborn ED, Wade TJ, Beach MJ, Yoder JS (2011) Surveillance for waterborne disease outbreaks and other health events associated with 
recreational water-United States, 2007-2008. MMWR Surveill Summ 60(12):1-32

Kelsall JE, Samet JM, Zeger SL, Xu J (1997) Air pollution and mortality in Philadelphia, 1974-1988. Am J Epidemiol 146(9):750-762

Kim BM, Lee BE, Hong YC, Park H, Ha M, Kim YJ, Kim Y, Chang N, Kim BN, Oh SY, Yoo M, Ha EH (2011) Mercury levels in maternal and cord blood and attained weight through the 24 months of life. Sci Total Environ 410(411):26-33

Lim G, Aramini J, Fleury M, Ibarra R, Meyers R (2002) Investigating the relationships between drinking water and gastroenteritis in Edmonton: 1993-1998. Health, Canada

Majidi NE, Bouchard M, Gosselin NH, Carrier G (2012) Relationship between prenatal exposure to polychlorinated biphenyls and birth weight: a systematic analysis of published epidemiological studies through a standardization of biomonitoring data. Regul Toxicol Pharmacol 64(1):161-176

McFee RB (2009a) Clostridium difficile: emerging public health threat and other nosocomial or hospital acquired infections. Introduction Dis Mon 55(7):419-421

McFee RB (2009b) Nosocomial or hospital-acquired infections: an overview. Dis Mon 55(7):422-438

Messner M, Shaw S, Regli S, Rotert K, Blank V, Soller J (2006) An approach for developing a national estimate of waterborne disease due to drinking water and a national estimate model application. J Water Health 4 Suppl(2):201-240

Morris RD, Naumova EN, Levin R, Munasinghe RL (1996) Temporal variation in drinking water turbidity and diagnosed gastroenteritis in Milwaukee. Am J Publ Health 86(2):237-239

Pruss A (1998) Review of epidemiological studies on health effects from exposure to recreational water. Int J Epidemiol 27(1):1-9

Roberts EM, English PB, Grether JK, Windham GC, Somberg L, Wolff C (2007) Maternal residence near agricultural pesticide applications and autism spectrum disorders among children in the California Central Valley. Environ Health Perspect 115(10):14821489

Rotkin-Ellman M, Quirindongo M, Sass J, Solomon G (2008) Deepest cuts: repairing health monitoring programs slashed under the Bush Administration

Schwartz J, Levin R, Goldstein R (2000) Drinking water turbidity and gastrointestinal illness in the elderly of Philadelphia. J Epidemiol Community Health 54(1):45-51
Schwartz J, Levin R, Hodge K (1997) Drinking water turbidity and pediatric hospital use for gastrointestinal illness in Philadelphia. Epidemiology 8(6):615-620

Sinclair MI, Fairley CK (2000) Drinking water and endemic gastrointestinal illness. J Epidemiol Community Health 54(10):728

Tinker SC, Moe CL, Klein M, Flanders WD, Uber J, Amirtharajah A, Singer P, Tolbert PE (2010) Drinking water turbidity and emergency department visits for gastrointestinal illness in Atlanta, 1993-2004. J Expo Sci Env Epid 20(1):19-28

US Environmental Protection Agency (2002) Clean water act, vol 33 USC 1251 et seq. Washington DC

US Environmental Protection Agency (2011a) Air pollution monitoring. http://www.epa.gov/airquality/montring.html\#montypes

US Environmental Protection Agency (2011b) National summary of impaired waters and TMDL information. http://iaspub.epa.gov/ waters10/attains_nation_cy.control?p_report_type=T\#status_of_ data

US Environmental Protection Agency (2011c) Overview of impaired waters and total maximum daily loads program. http://water.epa. gov/lawsregs/lawsguidance/cwa/tmdl/intro.cfm

US Environmental Protection Agency (2011d) What is the toxics release inventory program? http://www.epa.gov/tri/triprogram/ whatis.htm

Wade TJ, Pai N, Eisenberg JN, Colford JM Jr (2003) Do US environmental protection agency water quality guidelines for recreational waters prevent gastrointestinal illness? A systematic review and meta-analysis. Environ Health Perspect 111(8):1102-1109

Zanobetti A, Schwartz J (2009) The effect of fine and coarse particulate air pollution on mortality: a national analysis. Environ Health Perspect 117(6):898-903

\section{Disclaimer}

The views expressed in this article are those of the authors and do not necessarily reflect the views or policies of the US Environmental Protection Agency. Mention of trade names or commercial products does not constitute endorsement or recommendation for use. 